\title{
ALASDAIR MACINTYRE E O TOMISMO: NOTAS SOBRE THREE RIVAL VERSIONS OF MORAL INQUIRY
}

Alasdair MacIntyre and Thomism: notes on Three Rival Versions of Moral Inquiry

José Elielton de Sousa

UFPI/PUCRS

Resumo: O texto tematiza o tomismo em Alasdair Maclntyre, especialmente em Three Rival Versions of Moral Inquiry, mostrando como MacIntyre se apropria metodologicamente de ferramentas conceituais oriundas do tomismo para resolver os problemas que afligem a teoria e a prática moral contemporânea. Trata-se, portanto, de uma leitura hermenêutica do modo como Maclntyre se apropria do tomismo nessa obra específica, mas sem esgotar os elementos que compõem tal apropriação.

Palavras-chave: Tradição. Tomismo Metodológico. Hermenêutica.

Abstract: The paper thematizes the presence of Thomism in Alasdair Maclntyre, especially in his book Three Rival Versions of Moral Inquiry, by showing how Maclntyre appropriates methodologically conceptual tools coming from Thomism in to solve the problems that afflict the contemporary moral theory and practice. It is, therefore, a hermeneutic reading of how Maclntyre appropriates Thomism that particular work, but without exhausting the elements of such appropriation.

Keywords: Tradition. Methodological Thomism. Hermeneutics

\section{Introdução}

A reabilitação do tomismo na filosofia contemporânea tem no filósofo escocês Alasdair Maclntyre um de seus representantes mais inesperados. Com incursões pela filosofia analítica, pelo marxismo, pelo aristotelismo, entre outros, no chamado 
projeto "After Virtue"1 , o qual é tido como expressão de seu pensamento maduro, Maclntyre realizou uma verdadeira conversão filosófica ao cristianismo, mais precisamente operando um giro tomista em sua filosofia.

Na obra que inaugura tal projeto, After Virtue (2007), lançado em 1981, depois de diagnosticar o estado caótico em que se encontra a moralidade contemporânea e de apresentar a retomada da tradição clássica das virtudes como uma saída para tal situação caótica, MacIntyre termina o livro com a esperança na vinda de um novo São Bento para iluminar as trevas de nossos tempos bárbaros, numa clara filiação agostiniana. A obra seguinte, Whose Justice? Which Rationality? (1988), na qual Maclntyre oferece uma teoria da racionalidade das tradições para fundamentar sua afirmação da tradição das virtudes, contém um ponto de partida agostiniano e uma conclusão tomista. Mas é em Three Rival Versions of Moral Inquiry (1990) que o tomismo aparece definitivamente com toda força e clareza na filosofia macintyriana, a ponto de Maclntyre passar a se reconhecer e afirmar-se a partir daí como um aristotélico-tomista. Na obra seguinte, que complementa tal projeto, Dependent Rational Animals: Why Human Beings Need the Virtues (1999), Maclntyre corrige sua leitura da tradição aristotélica, notadamente sua recusa da biologia metafísica de Aristóteles, alinhando-a plenamente à perspectiva tomista.

Assim, se nas obras anteriores a Three Rival Versions of Moral Inquiry Tomás de Aquino aparece como um personagem periférico, a partir desta obra ele se torna um personagem central na configuração da teoria moral macintyriana. Contudo, esse giro realizado por Maclntyre em direção ao tomismo não é algo arbitrário e incoerente ou fruto de uma conversão repentina ao catolicismo de um antigo protestante; ele é

1 O projeto "After Virtue" é a expressão madura do pensamento de Alasdair Maclntyre, cuja trajetória e influência são organizadas num programa de pesquisa uniforme de crítica e superação da modernidade através da reabilitação da tradição aristotélica das virtudes numa perspectiva tomista, mas sem abrir mão das conquistas históricas e conceituais da filosofia contemporânea. Iniciado em 1981 com a publicação de After Virtue (2007), fazem parte dele ainda Whose Justice? Which Rationality?(1988), Three Rival Versions of Moral Enquiry (1990) e Dependent Rational Animals (1999), obras que formam uma tetralogia de enorme impacto na filosofia moral e política contemporânea. 
fruto de um esforço mais amplo de Maclntyre em reabilitar a tradição das virtudes como uma tradição de pesquisa racional.

Esse giro tomista na filosofia de Maclntyre tem sido objeto de análise, tanto por parte de seus partidários como por parte de seus críticos ${ }^{2}$. Normalmente, essas análises são focadas na correção ou não da leitura macintyriana de Tomás de Aquino e tem como objeto privilegiado de apreciação a apropriação, por parte do filósofo escocês, dos conceitos tomista de verdade (HALDANE, 1994), teleologia (COLEMAN, 1994) e lei natural (GEORGE, 1989). Em sua maioria, essas análises questionam tal apropriação do tomismo promovida por Maclntyre, acusando-o de operar transformações conceituais que tornam seu "tomismo" estranho ao próprio tomismo, apesar de presumivelmente haver elementos conceituais em Tomás de Aquino capazes de sustentar a leitura de Maclntyre (LUTZ, 2004). Felizmente não precisamos entrar nesse debate interno ao tomismo, apesar de reconhecer sua pertinência para uma melhor compreensão dos pressupostos teóricos da filosofia macintyriana.

Nesse sentido, o presente texto tematiza o tomismo em Alasdair Maclntyre, especialmente em Three Rival Versions of Moral Inquiry, mostrando como Maclntyre se apropria metodologicamente de ferramentas conceituais oriundas do tomismo para resolver os problemas que afligem a teoria e a prática moral contemporânea. Para isso, apresentaremos a caracterização macintyriana do desacordo entre tradições e o modo como, em sua leitura, Tomás de Aquino solucionou tais desacordos em sua época, dando continuidade e acabamento a uma tradição de pesquisa mais ampla e aberta a reformulações posteriores, a qual Maclntyre pretende reabilitar com vistas a resolver os nossos desacordos atuais. Trata-se, portanto, de uma leitura hermenêutica do modo como Maclntyre se apropria do tomismo nessa obra específica, mas sem esgotar os elementos que compõem tal apropriação.

\footnotetext{
2 Para uma visão detalhada sobre a análise do giro tomista na filosofia de Maclntyre, tanto por parte de seus partidários, como por parte de seus críticos, ver LUTZ, Christopher. Tradition in the Ethics of Alasdair Maclntyre. Lanham: Lexington Books, 2004.
} 
Enciclopédia, genealogia e tomismo: sobre os desacordos morais contemporâneos

O pano de fundo para a retomada do tomismo proposta por Maclntyre em Three Rival Versions of Moral Inquiry é uma tese já defendida em After Virtue e Whose Justice? Which Rationality?, segundo a qual habitamos uma cultura marcada por conflitos e desacordos incomensuráveis e aparentemente irresolúveis. Segundo Maclntyre, o alcance destes conflitos e desacordos é tão geral e o caráter de alguns deles é tão sistemático que "não é exagero falar de concepções rivais de racionalidade, tanto teórica quanto prática" (MacINTYRE, 1990, p. 13).

Diante de um cenário de desacordos profundos, Maclntyre oferece um exemplo concreto de sua proposta de uma racionalidade das tradições de pesquisa moral $^{3}$ por meio da defesa da tradição aristotélico-tomista frente à genealogia de matriz nietzschiana e à perspectiva iluminista da Enciclopédia Britânica. Para ele, apesar das diferenças profundas e irreconciliáveis que separam essas duas perspectivas, ambas as partes conflitantes estão de acordo, em grande medida, se não inteiramente, no modo como concebem a história da filosofia desde Sócrates até o século XIX.

Para o enciclopedista, esta história é a do progresso da razão, na qual as limitadas concepções de raciocínio e de práticas da investigação racional geradas por Sócrates, Platão e Aristóteles, foram ampliadas por seus sucessores, embora com novas limitações, e logo receberam forma definitiva e indefinidamente melhor por obra de Descartes. [...] Para o genealogista, esta história tem um caráter muito diferente. É uma história em que a razão, desde a dialética de Sócrates até os pós-kantianos, tanto serve como disfarça os interesses da vontade de poder devido às suas pretensões injustificadas. Onde o enciclopedista vê uma história unificada de progresso, o genealogista vê uma história de deformidade e repressão. Entretanto, ambos concordam, ao menos, em supor uma história unificada (MacINTYRE, 1990, p. 58-59).

Ambos, portanto, discordam de qualquer visão que entenda a história da filosofia em função de uma ruptura fundamental, de tal maneira que a filosofia tenha

\footnotetext{
3 Para uma análise do conceito de pesquisa racional constituída pela tradição e dela constitutiva, ver CARVALHO, Helder B. A. Tradição e racionalidade na filosofia de Alasdair Maclntyre. 2a ed. Teresina: EDUFPI, 2011.
} 
uma história dividida, um antes e um depois, cuja caracterização do antes será uma tarefa muito diferente da caracterização do depois.

Para Maclntyre, esta visão que entende a história da filosofia em função de uma ruptura fundamental foi adotada pela leitura que Joseph Kleutgen faz do tomismo em sua obra Die Philosophie der Vorzeit Verteidigt, publicada em quatro volumes em Munique entre 1853 e 1860. Em suas palavras,

O que Kleutgen distinguiu foi essa filosofia que vai de Sócrates à Alta Idade Média, e que tomou sua forma definitiva nos escritos de Tomás de Aquino, e essa outra filosofia que reconhece Descartes como seu destacado progenitor. Assim, onde tanto os enciclopedistas como os genealogistas haviam retratado continuidade, Kleutgen retratou ruptura (MacINTYRE, 1990, p. 59).

Essa percepção de Kleutgen ainda no século XIX é uma chave importante para a compreensão macintyriana de que a razão só pode ser autenticamente universal e impessoal, como queriam tanto os enciclopedistas como os genealogistas, na medida em que não é nem neutra e nem desinteressada, mas pertencente a um tipo particular de comunidade filosófica. Segundo Maclntyre,

\begin{abstract}
Foi justamente essa possibilidade a apresentada por Platão ao iniciar a tradição filosófica, particularmente no Górgias e na República. O que resultou do confronto de Sócrates com Cálicles no Górgias foi que uma condição prévia para o engajamento em uma investigação racional mediante o método dialético é que possua e reconheça certas virtudes morais sem as quais o progresso cooperativo na dialética se torna impossível, algo que, ademais, reconheceu Platão na República, ao identificar aquelas virtudes cuja prática tem que preceder à iniciação na comunidade filosófica, e Aristóteles, ao se dar conta da inseparabilidade das virtudes morais e das intelectuais, tanto na comunidade política como na filosofia (MacINTYRE, 1990, p. 60).
\end{abstract}

Assim, da perspectiva socrática, a investigação da natureza das virtudes e do bem humano em geral, se for desinteressado, se torna estéril; uma investigação racional requer um compromisso prévio e a natureza deste compromisso inicial determina de maneira parcial e crucial as conclusões que surgem como progresso dessa investigação. Na leitura macintyriana, do ponto de vista do Górgias e da 
República, o investigador terá de aprender como converter-se a si mesmo em um tipo particular de pessoa se quiser chegar ao conhecimento da verdade sobre seu bem e sobre o bem humano em geral. Mas que tipo de transformação é exigido? Para Maclntyre,

\begin{abstract}
É aquela que envolve converter-se a si mesmo em um aprendiz de uma arte, a arte, neste caso, da investigação filosófica. Pois parte daquilo posto pela tradição filosófica que vai de Sócrates a Tomás de Aquino em conflito com o pensamento filosófico da modernidade, seja enciclopédico ou genealógico, foi tanto seu modo de conceber a filosofia como uma arte, uma techne, como sua concepção de o que é tal arte em boas condições (MacINTYRE, 1990, p. 61).
\end{abstract}

Maclntyre utiliza o termo techne no sentido aristotélico, segundo o qual o que uma techne particular produz naqueles que a praticam é certa capacidade particular de realizar-se somente a partir de um raciocínio verdadeiro, que requer, por sua vez, tanto as virtudes intelectuais como as morais. Segundo Maclntyre, ao defender na Ética a Nicômaco e na Metafísica que comprometer-se a ser um philosophos é embarcar numa techne, "Aristóteles claramente apenas repetiu o que ele aprendeu de Sócrates e Platão. E quando na Idade Média conceitos de arte são usados para caracterizar a investigação [...] foi em Platão e Aristóteles que esses autores se apoiaram para comunicar essa concepção de prática" (MacINTYRE, 1990, p. 61).

Em que consiste, então, essa concepção de investigação racional como uma arte, que Maclntyre está defendendo? O que existe na estrutura de uma arte que é importante para a investigação filosófica? Maclntyre destaca duas caraterísticas notáveis: primeiramente, em toda arte o aprendiz tem que aprender, em princípio de seus mestres e, em seguida, através de sua autoeducação, como identificar os erros que ele mesmo comete ao aplicar os critérios que se reconhecem como aqueles dos quais melhor se dispõe nesse momento na história dessa arte particular; em segundo lugar, o aprendiz tem que aprender a distinguir entre a classe de excelência que tanto outros como ele podem esperar dele mesmo aqui e agora e aquela excelência última que proporciona seu telos tanto aos aprendizes como aos mestres artesãos 
(MacINTYRE, 1990, p. 61-62). Deste modo, o aprendiz aprende que vícios devem ser erradicados e que virtudes morais e intelectuais devem ser cultivadas.

Para Maclntyre, "esta necessidade de identificar tais virtudes e de adquiri-las para aprender tudo aquilo em que, nessa arte particular, exige um ser instruído, tem consequências particularmente importantes quando a arte em questão é, ou inclui, a investigação moral" (MaclNTYRE, 1990, p. 62). As virtudes são necessárias para a prática de qualquer techne, se esta techne estiver dirigida a um bem autêntico, pois o exercício de uma techne não determina por si mesmo a que fim se dirigirá este exercício. Segundo MacIntyre, portanto,

O telos da investigação moral, que é a excelência na consecução, não apenas de uma compreensão teórica adequada do bem especificamente humano, mas também da encarnação prática dessa compreensão na vida do investigador particular, exige não apenas uma arte, mas, sobretudo, uma arte guiada pela virtude (MacINTYRE, 1990, p. 62-63).

Essa concepção de prática de investigação moral pressupõe um mestre que nos ponha em condições de atualizar nossa potencialidade em buscar e obter conclusões teóricas e práticas pertinentes, aprendendo e aceitando inicialmente precisamente que hábitos intelectuais e morais são os que temos que adquirir e cultivar se quisermos ser efetivos participantes autônomos em semelhante investigação ${ }^{4}$. Segundo Maclntyre, o participante de uma arte é racional enquanto participante na medida em que se ajusta aos melhores critérios da razão descobertos até esse momento; e essa racionalidade da qual participa se entende sempre como uma racionalidade historicamente situada, embora aspire uma formulação eterna de seus próprios critérios, o que seria sua forma final e acabada, através de uma série de

\footnotetext{
4 Parece haver aqui uma relação direta entre dois conjuntos conceituais fundamentais em Tomás de Aquino, a saber, sua teoria ética das virtudes e sua teoria da lei natural. Contudo, surpreendentemente MacIntyre não menciona essa relação quando trata das virtudes neste pensador; a única vez que ele assume a ideia de lei natural tomista, mas sem dar maiores detalhes acerca desta sua adesão, é quando ele, em Dependent Rational Animals, ao se referir ao fato de que as virtudes necessárias ao florescimento humano envolvam um componente normativo e que tal componente são os preceitos da lei natural tomista (Cf. MacINTYRE, 1999, p. 109-112).
} 
reformulações sucessivas, posteriores e, todavia, por alcançar (MacINTYRE, 1990, p. 64-65).

Ora, segundo Maclntyre, entender a investigação moral como uma techne implica uma hierarquia das artes, na qual a sapientia é a virtude específica da atividade filosófica, tal como a entendeu Tomás de Aquino, seguindo as interpretações platônica e aristotélica. Nessa hierarquia, algumas artes estão subordinadas às outras e essas artes mestras têm relações com aspectos importantes, mas não universal, da vida humana, tais como a medicina, a política, a arquitetura, etc., de modo que os praticantes destas últimas podem ser considerados sapientes de maneira limitada. Nesse sentido, Maclntyre salienta o papel central que a filosofia desempenha, pois

\begin{abstract}
Sapientes como tais são apenas os que se ocupam em suas investigações com os primeiros princípios e as causas últimas, não deste ou daquele conjunto de verdade, mas com a aquisição da scientia desta veritas que é a origo de toda veritas. A filosofia é, portanto, a arte mestra das artes mestras (MacINTYRE, 1990, p. 68).
\end{abstract}

O que Maclntyre está defendendo com essa concepção de investigação moral como uma techne é uma leitura específica do tomismo a partir de certa interpretação da Aeterni Patris do Papa Leão XIII. Para os que seguem essa perspectiva, aqueles que aparecem mais tarde, muitas vezes, tiveram que corrigir e completar as investigações de seus predecessores, mas no sentido de um progresso real, de tal maneira que, apesar da multiplicação de tomismos sistemáticos, ao aparecer o desacordo, os investigadores históricos do movimento tomista se lhes opuseram com sua explicação da empresa de Tomás de Aquino ${ }^{5}$. Segundo MacIntyre,

Essa explicação apresenta o desenvolvimento do pensamento do Aquinate, através de sua carreira, [...] como o resultado de sua participação em um modo de investigação - assim como da representação cada vez mais adequada que dele se formou - que era a continuação, dialeticamente não limitada de antemão, dessa tradição de uma arte que provém de Sócrates,

\footnotetext{
5 Sobre as perspectivas interpretativas da reabilitação do tomismo na filosofia contemporânea, especialmente a leitura macintyriana, ver LUTZ, 2004.
} 
Platão e Aristóteles, assim como dos Padres da Igreja, tradição da qual a Aeterni Patris falou com grande precisão, porém cujo caráter não foram capazes de entender com frequência os leitores da Aeterni Patris (MacINTYRE, 1990, p. 77).

Nesse sentido, afirma Maclntyre, é crucial para o reestabelecimento e continuação do tomismo que se reconheça que não cabe explorar de modo adequado a verdadeira natureza do conflito entre esta perspectiva teórica e outras perspectivas modernas atendendo às suas teses individualmente, mas em sua relação global com cada modo específico de investigação. Reconhecer isso implica reconhecer outra dimensão de diferença e conflito, a qual se refere ao modo como cada perspectiva considera apropriado voltar a contar e a representar as narrações da vida moral. Isso resultará, como defenderá Maclntyre,

Que é contrastando e comparando os modos diferentes e rivais no que cada perspectiva entende a estrutura de tais narrações, como podem definir-se do modo mais fácil assuntos que os dividem, e talvez resolvê-los, embora isso também resulte que parte dos que estão em discussão é a questão do que - no caso de ter algo - poderia considerar como uma resolução (MacINTYRE, 1990, p. 78).

A estrutura narrativa do enciclopedista é uma estrutura que vem ditada pela crença no progresso da razão e a vida do indivíduo adquire uma estrutura narrativa com sentido na medida em que participa desse progresso. Para o genealogista, por sua vez, este apelo a princípios racionais eternos tem a função de ocultar o peso de um passado que não foi descartado inteiramente e a concepção unitária da razão, em cujo nome se faz esta apelação, tem correspondente função de proporcionar um estatuto privilegiado e injustificado aos que identificam suas próprias afirmações e argumentos com as versões da razão concebida deste modo. Para Maclntyre,

A narração tomista, diferentemente destas duas, não trata o passado nem como um mero prólogo nem como algo contra o qual temos que lutar, mas como aquilo com que temos que aprender, se é que temos de identificar e de mover-nos até nosso telos mais adequadamente, e como aquilo que teremos que questionar, se é que temos que conhecer que questões 
teremos que debater de imediato e tentar responder, tanto de maneira teórica como prática (MacINTYRE, 1990, p. 79).

Assim, estas três perspectivas se opõem entre si não apenas como teorias morais rivais, mas também como projetos de construção de formas rivais de narração moral. E a prevalência de uma sobre as outras, afirma Maclntyre, é determinada pela capacidade de uma narrativa incluir suas rivais dentro dela, não apenas recontando a história do relato da história de suas rivais como episódios dentro de sua história, mas de contar a história do relato das histórias de suas rivais como tais episódios ${ }^{6}$.

\title{
Agostinismo e aristotelismo: duas tradições rivais e incomensuráveis
}

Um exemplo paradigmático de tal procedimento de investigação é o fornecido por Tomás de Aquino. Para Maclntyre, o tomismo emergiu do conflito entre duas tradições rivais e, aparentemente, irreconciliáveis entre si: a tradição agostiniana e a tradição aristotélica. Segundo ele,

\begin{abstract}
A filosofia e a teologia de Tomás de Aquino foram uma resposta ao conflito e é, portanto, a partir desse conflito onde começa toda a discussão tomista, considerando e avaliando as pretensões aparentemente antagônicas do agostinismo, pois o Aquinate foi certamente um agostiniano, e do aristotelismo, pois Tomás de Aquino foi igualmente certo um aristotélico (MacINTYRE, 1990, p. 81).
\end{abstract}

Em que consistia tais conflitos? E como Tomás de Aquino superou-os? Na cultura medieval, a relação entre os textos chaves dessa cultura - A Sagrada Escritura e seus leitores era dupla: ao leitor era atribuída a tarefa de interpretar o texto, mas também tinha que descobrir, em sua leitura e mediante essa leitura, que esses textos, por sua vez, interpretam o leitor, de modo que o leitor se descobre a si mesmo dentro das Escrituras. Segundo MacIntyre, "o documento paradigmático de semelhante

\footnotetext{
6 Sobre os elementos teórico-filosóficos envolvidos na elaboração do tomismo como uma via media entre o relativismo radical da genealogia e o racionalismo universalista do enciclopedista, John Haldane afirma que "Maclntyre parece oferecer apenas este realismo filosófico teísta comprometido com uma visão dos objetos da razão como mente independente, mas um realismo que sustenta que a própria razão é moldada e avançou através de tradições de investigação" (HALDANE, 1994, p. 104).
} 
descoberta foram as Confissões de Agostinho, e foi certamente Agostinho quem formulou de forma clássica a doutrina da compreensão que impregnou a tradição medieval, uma concepção platônica à qual Agostinho deu forma cristã" (MaclNTYRE, 1990, p. 83).

Dessa relação entre leitor e texto se fez necessário o desenvolvimento de uma tradição de comentário e de interpretação, tradição que tomou como modelos os comentários das Escrituras que fizeram Agostinho e Jerônimo. No interior dessa tradição, apesar da obtenção de grandes acordos, se desenvolveram também um conjunto de disputas sobre temas que geraram desacordos entre comentadores e intérpretes rivais. Para Maclntyre, uma questão central que motivou tais desacordos foi "o reconhecimento de que toda passagem de um texto poderia ter mais de um sentido: um sentido somente histórico, um sentido moral ou tropológico, um sentido alegórico ou místico e, em alguns escritores, um quarto sentido, um sentido espiritualmente educativo ou análogo" (MacINTYRE, 1990, p. 85).

Além dessa doutrina da multiplicidade de sentidos do texto, que multiplicou também as ocasiões para o desacordo interpretativo e a controvérsia, Maclntyre elenca ainda como aspectos importantes desses desacordos e controvérsias: a) a concepção de philosophia do século XII, a qual designa a investigação como tal, e suas matérias e teses filosóficas se organizam como partes de tipos diferentes de investigação em diferentes tipos de contextos e com diferentes origens; b) a aplicação da dialética em questões teológicas, a qual tem sempre um caráter essencialmente incompleto e provisório, na medida em que argumenta em direção aos primeiros princípios (dialética ascendente); c) e o sistemático aumento da produção de distinções segundo os tipos de sentido, não apenas na explicação das Escrituras, mas também na compreensão dos textos seculares, de tal forma que, com o tempo, surge um novo gênero, uma série de obras intituladas Distinctiones (MacINTYRE, 1990, p. 8789). Assim, quando justapostas a heterogeneidade das fontes filosóficas herdadas do mundo antigo e a multiplicidade de quaestiones e distinctiones, se evidencia as 
grandes possibilidades de radical desacordo intelectual, mesmo dentro das restrições impostas pelo marco agostiniano.

Segundo Maclntyre, o sistema agostiniano era vulnerável de dois modos diferentes: como toda tradição de pesquisa intelectual e prática desenvolvida, por um lado, tinha sua própria problemática interna concernente a uma série de questões discutida dentro da tradição e, por outro lado, tinha a problemática externa, a qual obrigava seus partidários a dar respostas a seus adversários ou ao menos tentar. Nesse sentido, do ponto de vista interno, a tradição agostiniana enfrenta três tipos de problemas:

\begin{abstract}
O primeiro é um enfrentamento de todo tipo de platonismo. Se entender um particular é entendê-lo em sua relação com uma forma universal, somente a cuja luz pode fazer-se inteligível esse particular, qual é a natureza dessa relação? [...] Um segundo conjunto de problemas se refere ao papel que desempenha a iluminação divina na geração do conhecimento na mente criada. As dificuldades neste ponto surgem da incompatibilidade aparente de uma variedade de afirmações do próprio Agostinho. [...] Em terceiro lugar, tanto Agostinho como os agostinianos apresentam a separação humano de seu bem como algo que se deve à perversidade da vontade. [...] Contudo, a doutrina agostiniana falhou em explicar suficientemente como o entendimento se refere ou referia ao bem antes e independentemente da condução errônea da vontade (MacINTYRE, 1990, p. 100-101).
\end{abstract}

Além desses problemas internos, Maclntyre afirma que a tradição agostiniana enfrentou outro problema: a descoberta da filosofia de Aristóteles em toda sua integridade. Um problema que atingiu não apenas as questões sobre a verdade das doutrinas teológicas fundamentais, mas também o esquema de estudos agostiniano e a explicação do conhecimento que esse plano de estudos pressupunha (MacINTYRE, 1990, p. 102). O aristotelismo, tal como exposto pelos comentadores islâmicos, por um lado, proporcionou um conjunto de textos científicos naturais que atribuíram às ciências naturais um conteúdo e uma importância inteiramente alheias ao agostinismo, tal como tinha sido formulado até o momento, e por outro, proporcionou explicações do que é uma ciência, do que é o telos de uma investigação, que estavam 
notadamente em desacordo com a versão agostiniana do platonismo, sobretudo por não deixar espaço e nem ter necessidade, em sua explicação da gênese do conhecimento, da iluminação divina. Maclntyre afirma que o desacordo era tal que, "em certos aspectos, parecia dar-se o caso de que o esquema agostiniano só podia ser verdadeiro se o aristotélico fosse falso, e vice-versa" (MacINTYRE, 1990, p. 103).

$\mathrm{Na}$ visão de Maclntyre, as incoerências radicais entre essas duas tradições surgiram em três níveis. O primeiro nível, que envolve a autoridade eclesiástica e teológica, se refere às doutrinas cristãs centrais. Nesse nível,

Onde Aristóteles afirmava a eternidade do mundo, o cristianismo the atribuía o começo no momento da criação; onde Aristóteles excluía a existência imaterial separada da alma individual e onde a interpretação que fez Averróis do De Anima, mas deixou espaço para a ressurreição dos mortos, reforçava a negação de toda sobrevivência da alma separada do corpo, o cristianismo se colocava a favor dessa sobrevivência (MacINTYRE, 1990, p. 107).

O segundo nível em que o aristotelismo e seus intérpretes desafiaram o agostinismo diz respeito à organização e à estrutura da investigação. Assim, afirma Maclntyre, "mesmo antes de 1240, começou a ficar claro que o que foi colocado em questão foi a organização e a estrutura da investigação estabelecida e, em especial, a relação da teologia com as outras disciplinas dentre dessa organização e dessa estrutura, e não apenas esta ou aquela tese particular" (MacINTYRE, 1990, p. 108).

O terceiro nível desse desacordo envolve três campos distintos, mas interrelacionados: a) teoria da mente: enquanto que para Aristóteles, uma caracterização adequada da mente é a que descreve a mente obtendo o conhecimento, para Agostinho, é a que descreve a mente como não sendo capaz, por si mesma, de conhecer, mas somente apoiando-se em certa fonte externa (a iluminação divina) que Ihe provê o conhecimento; b) concepção de verdade: Aristóteles coloca a verdade na relação da mente com seus objetos, Agostinho, por sua vez, a coloca na fonte da relação dos objetos finitos com essa verdade que é Deus; c) e a natureza do defeito e do erro: enquanto que Aristóteles, como todo autor antigo pré-cristão, não teve 
nenhum conceito de vontade e não há nenhum espaço conceitual em seu esquema para essa noção estranha nas explicações do defeito e do erro, para Agostinho, a vontade é a causa mais importante do erro (MacINTYRE, 1990, p. 110-111). Desta maneira, o filósofo aristotélico e o teólogo agostiniano apelam a critérios rivais e incomensuráveis tanto na avaliação como na explicação das questões investigadas.

Esse conflito é um exemplo clássico de incomensurabilidade entre dois esquemas conceituais alternativos e rivais. Como já exposto em obras anteriores (especialmente em Justiça de quem? Qual racionalidade?), Maclntyre afirma que esta incomensurabilidade não pode ser reconhecida e caracterizada adequadamente por quem vive apenas em um dos esquemas conceituais opostos, mas somente por alguém que vive em ambos os esquemas conceituais conflitantes, alguém que conheça e seja capaz de falar a linguagem de cada um desde uma perspectiva interna (MacINTYRE, 1990, p. 113-114). Segundo ele, tais pessoas são pouco numerosas, são os "habitantes" de situações de fronteiras, que em geral incorrem em suspeita e em incompreensão pelos membros de ambas as tradições em conflito - como ocorreu com Tomás de Aquino tanto por parte de alguns agostinianos como por parte de alguns aristotélicos averroístas latinos, e ocorreu com ele [Tomás de Aquino] justamente porque ele era uma dessas pessoas (MacINTYRE, 1990, p. 114-115).

\section{Tomás de Aquino e a racionalidade da tradição}

Para Maclntyre, dentre os discípulos de Alberto Magno, o primeiro agostiniano a se propor a enorme tarefa de apresentar o aristotelismo em seus próprios termos, Tomás de Aquino, o mais notável, foi o único a confrontar sistematicamente as pretensões rivais desses dois pontos de vista alternativos e, aparentemente, incomensuráveis. Segundo ele, "somente Tomás de Aquino parece ter mergulhado profundamente tanto no aristotelismo como no agostinismo, a ponto de fazer destes um problema central, não apenas de suas investigações intelectuais, mas também de sua existência" (MacINTYRE, 1990, p. 115). O Aquinate tinha que lidar, portanto, com duas tradições rivais e incomensuráveis, cada uma com sua própria 
história e seu próprio modo de investigação desenvolvido e em desenvolvimento, cada uma requerendo sua própria encarnação institucional.

Ora, como vimos acima, conceber a investigação racional como uma techne implica dizer que toda tradição de investigação tem um ponto de partida histórico, contingente, no qual se põe em questão certa série de crenças estabelecidas e de práticas que supõem essas crenças. Dessa forma, afirma Maclntyre,

\begin{abstract}
Uma tradição atravessará diversas etapas, cada uma das quais proporcionará uma justificação do esquema de crença como um todo em função de sua superioridade racional frente às formulações da etapa precedente, a qual, por sua vez, poderia justificar-se através de uma nova referência anterior. Contudo, a disponibilidade deste tipo de referência do presente ao passado não é suficiente por si mesma para constituir uma tradição de investigação racional. É necessário também que surja certa continuidade na direção, de tal forma que se formule as metas teóricas e práticas que guiam a investigação e se reformule em fases posteriores (MacINTYRE, 1990, p. 116).
\end{abstract}

Na medida em que uma tradição racionalmente madura atravessa várias de suas etapas, entre as crenças e as práticas que estão sujeitas à reformulação estão, tanto as que se refere ao que já foi avaliado como racional e verdadeiro, como aquelas que se referem às metas teóricas e práticas dessa tradição particular. Assim, o que constitui a racionalidade de uma tradição só pode ser respondido adequadamente recorrendo a certo ponto de vista particular, ou seja, o que constitui o critério de verdade e de racionalidade, tanto teórica quanto prática, de uma tradição é intrínseco a essa tradição ${ }^{7}$.

Mas como, então, conciliar pontos de vista rivais e aparentemente inconciliáveis, tal como fez Tomás de Aquino ao integrar os modos de compreensão agostiniano e aristotélico em uma síntese unificada? Maclntyre elenca ao menos três

\footnotetext{
7 É com base em asserções como essa que Carlos Isler (2011) defende a tese de que Maclntyre é um relativista conceitual e não um tomista, como o próprio pensador escocês se autodefine. Para ele, o relativismo conceitual e em especial a doutrina de Maclntyre de que devemos ver os outros através dos conceitos deste é bastante anterior a sua conversão ao tomismo e ao aristotelismo (Cf. ISLER, 2011, p. 109).
} 
casos em que a incomensurabilidade implicada em certos desacordos radicais pode ser reconhecida e superada.

Primeiramente, ainda que não seja possível que um sistema anterior de pensamento sustente conclusões de uma segunda teoria, contudo, os que vivem e construíram o último sistema, talvez, uma vez que viveram e atuaram no primeiro, podem ser capazes de incluir dentro deste sistema uma representação adequada de seu predecessor. Eles podem inclusive explicar como ocorreu essa mudança, mostrando as limitações da primeira teoria em solucionar seus próprios problemas, formulados em seus próprios termos, ainda que esta última se abra a uma nova problemática (MacINTYRE, 1990, p. 119).

Em segundo lugar, a mudança do primeiro ponto de vista para o último justifica-se de forma retrospectiva, não apenas em razão da esterilidade do primeiro, mas também porque esta esterilidade pode agora ser explicada e não aparecer apenas como um fato bruto e inexplicável. Assim, este raciocínio retrospectivo justifica o raciocínio prospectivo que possibilita obter um novo ponto de vista e não apenas um único ponto de vista. O raciocínio prospectivo nesse tipo de casos é dialético, exploratório, inventivo e provisional, formulando hipóteses à medida que se encaminha rumo a uma nova série de primeiros princípios e de concepções fundamentais. Somente quando estes são alcançados satisfatoriamente é que se pode justificar o que até esse momento era exploratório, hipotético (MacINTYRE, 1990, p. 119).

Em terceiro lugar, nunca podemos excluir a possibilidade de compreender o outro ponto de vista incomensurável desde dentro de maneira imaginativa. É pelo uso da imaginação que podemos viver em uma cultura alheia e ao fazê-lo descobrir como descobrir-se e caracterizar-se, desde o ponto de vista de outra cultura, traços importantes de nossa própria cultura para os quais até o momento estávamos cegos (MacINTYRE, 1990, p. 120). Assim, Tomás de Aquino reconheceu as limitações do agostinianismo desde uma perspectiva agostiniana e as limitações do aristotelismo 
desde uma perspectiva aristotélica, caracterizando-os suficientemente e transcendendo-os de um modo que ambos os pontos de vista não poderiam fazer um a respeito do outro, realizando dessa forma, aquilo que mais tarde Gadamer vai chamar hermeneuticamente de "fusão de horizontes"8 (GADAMER, 1997, p. 400-465).

Contudo, para evitar cair num perspectivismo relativista, Maclntyre afirma que "temos que entender a verdade de um modo particular" (MacINTYRE, 1990, p. 121). Em vez de entender e julgar a incomensurabilidade como um problema de tradução para sua própria linguagem, para seus próprios modismos conceituais, não se dando conta das particularidades e parcialidades radicais do próprio ponto de vista, ele defende que devemos desenvolver uma pretensão de verdade que apele para critérios que estão além de um esquema particular de conceitos e crenças, que apela para algo externo a essa esquema. Assim, na visão macintyriana,

\begin{abstract}
Ao julgar a verdade, há sempre certa referência inaudita além do esquema dentro do qual se faz esses juízos e mais além dos critérios que garantem as afirmações dentro desse esquema. A verdade não pode ser identificada com afirmação justificada nem se reduz a ela. $E$, em correspondência, é requerida uma concepção do que é o que é mais do que uma concepção do que parece ser o caso à luz dos critérios mais fundamentais que governam a afirmação dentro de um esquema particular, isto é, faz-se necessário uma metafísica do ser, do esse, sobre e acima do que pode ser dito sobre os entia particulares à luz de conceitos particulares (MacINTYRE, 1990, p. 122).
\end{abstract}

Segundo Maclntyre, não é por acaso que entre as primeiras obras que Tomás de Aquino começou a definir seu ponto de vista definitivo estejam De Ente et Essentia e Quaestiones De Veritate, as quais são dicionários filosóficos em que se explicam os vários usos de "verdadeiro", "verdade", "ser" e "essência"; usos estes que se relacionam analogicamente e se aplicam primeiramente a Deus, do qual deriva tudo o que é. Contudo, como é daquilo que é derivado que temos que partir, entender as relações analógicas é também compreender as relações causais em função das quais se fazem inteligíveis os estados e as mudanças presentes de todos os seres finitos, bem

8 Sobre a influência da hermenêutica de Gadamer na filosofia de Alasdair Maclntyre, ver CARVALHO, 2013. 
como as relações práticas através das quais todos os seres finitos se movem até seu fim acabado. Deste modo, os seres finitos se fazem inteligíveis enquanto se movem e são movidos, e as estruturas através das quais se fazem assim inteligíveis são aquelas que relacionam, em vários aspectos, todos os seres com sua primeira causa enquanto motor imóvel, que já não está determinado nem é determinado por nenhuma outra coisa (MacINTYRE, 1990, p. 122-123).

$\mathrm{Na}$ leitura de Maclntyre, são estas as estruturas analisadas e reveladas nas Quinque Viae da Summa Theologiae, cada uma das quais, explicada de maneira analógica, causal e prática, permitiu a integração de ambos os esquemas rivais (agostiniano e aristotélico), não apenas corrigindo em cada um deles o que considerava, com base em seus próprios critérios, defeituoso ou infundado, mas também afastando de cada um, de uma maneira justificada por essa correção, aquilo que Ihes impedia de reconciliação. Nesse sentido, "retrospectivamente podemos entender Tomás de Aquino como tendo salvado ambos os pontos de vista de eminentes, embora não reconhecidas, crises epistemológicas" (MacINTYRE, 1990, p. 123).

Para Maclntyre, Tomás de Aquino, ao se apropriar de ambas as tradições, integrando-as e revisando o que era específico de cada uma, o fez mediante um método que requeria que sua própria obra continuasse essencialmente incompleta. $\mathrm{A}$ conjunção deste requisito com as tarefas de síntese e de unificação produziram um novo gênero para o discurso da investigação, primeiro, na maneira em que o Aquinate articulou séries sistemáticas nas Quaestiones Disputatae, e mais tarde, notavelmente na Summa Theologiae. Assim,

Ainda que as conclusões de cada questão particular sejam integradas numa estrutura demonstrativa global e hierárquica, que representa o ponto alcançado até esse momento na busca por uma ciência finalmente acabada, ou ainda, até uma hierarquia de ciências finalmente acabadas, na qual a teologia se encontra no ápice, contudo, em cada questão, a resposta que Tomás de Aquino oferece como conclusão não é mais e, dado o método do Aquinate, não pode ser mais que a melhor resposta alcançada até este momento. É daqui que se deriva o caráter essencialmente incompleto. [...] 
Seu método sempre deixa aberta a possibilidade de se voltar sobre uma questão com algum novo argumento (MacINTYRE, 1990, p. 124-125).

A Summa é, dessa forma, uma obra em processo de elaboração. Isso não significa, contudo, ressalta Maclntyre, que ela está inacabada, mas apenas que o Aquinate levou seus argumentos tão longe quanto pôde a ponto de cada argumento particular poder ser retomando posteriormente (salvo na Escritura Sagrada e na tradição dogmática), sendo a investigação, por conseguinte, um procedimento essencialmente incompleto, dialético, tal como o entendia Platão e Aristóteles. Nesse sentido, o tomismo, tal como o entende Maclntyre, dá continuidade e acabamento a uma tradição de pesquisa mais ampla e aberta a reformulações posteriores, a qual Maclntyre pretende reabilitar com vistas a resolver os conflitos entre tradições que caracterizam a filosofia contemporânea.

Ao caracterizar o tomismo dessa forma, Maclntyre passa a desenvolver um exemplo concreto de discussão filosófica, defendendo a tradição aristotélico-tomista contra outras duas tradições que lhe são adversárias ${ }^{9}$. Pois segundo ele,

O tomismo confronta, tanto as pretensões substantivas da enciclopédia do final do século XIX e de seus herdeiros do século XX, como as pretensões subversivas da genealogia com seus compromissos, aqueles compromissos que se abrem a juízos radicais sobre seu próprio sucesso ou fracasso, compromissos pelos quais exibe os tipos de vulnerabilidade intelectual que são a marca de toda teorização digna de interesse (MacINTYRE, 1990, p. 125).

Para dar conta dos conflitos entre tradições, Maclntyre opera com um conceito de racionalidade internalista. Recorrendo ao método empregado por Tomás de Aquino para enfrentar os conflitos de seu tempo, Maclntyre afirma que

A estratégia do Aquinate, se eu tiver entendido ele corretamente, foi pôr os agostinianos em condições de entender como, por seus próprios critérios,

\footnotetext{
9 Segundo Helder B. A. de Carvalho, "seu propósito é demonstrar a vitalidade da tradição aristotélicotomista diante de um cenário pós-kantiano, dentro de um arcabouço hermenêutico, pós-virada linguística" (CARVALHO, 2013, p. 314).
} 
eles enfrentaram problemas, contanto que eles se mantivessem dentro dos limites de seu próprio sistema, para cujo tratamento adequado careciam de recursos necessários; e de modo paralelo, proporcionar a mesma forma de compreensão para os aristotélicos averroístas. Assim também, necessitamos proceder pleiteando questões críticas para os enciclopedistas e os genealogistas, não em nossos termos, mas nos seus próprios termos (MacINTYRE, 1990, p. 173).

Para o genealogista, o problema seria sua concepção de identidade pessoal, enquanto que, para o enciclopedista, seria a moralidade mesma. No caso dos enciclopedistas, para a maioria deles, a moralidade não tem história, precisamente porque obtém o mesmo acordo sobre as normas e as concepções de dever e obrigação em todas as sociedades, razão pela qual “o propósito do filósofo moral devia ser o de articular um consenso racional além das crenças e dos juízos pré-teóricos das pessoas comuns" (MacINTYRE, 1990, p. 177). Os enciclopedistas afirmam a superioridade racional de sua postura diante de qualquer outra e, por conseguinte, avaliam o fracasso e as limitações dessas outras posturas a partir de seus próprios critérios e não nos próprios termos delas, cuja consequência foi o surgimento de um alto grau de indeterminação.

Quanto ao problema da identidade levantado pelos genealogistas, Maclntyre afirma que, "ao rechaçar todos os traços da responsabilidade, entendidos em função da dialética socrática ou da confissão agostiniana, o genealogista tornou impossível satisfazer, ao menos, as condições para atribuir a identidade e a continuidade que implicam a responsabilidade" (MacINTYRE, 1990, p. 205). Isso implica dizer que não há como pleitear questões sobre a identidade, a responsabilidade, a unidade e a continuidade do eu dentro de uma estrutura genealógica. Segundo a argumentação macintyriana, entretanto, o genealogista não pode incluir legitimamente em sua narração genealógica o próprio eu pelo qual ele fala quando se explica. Nesse sentido, o genealogista se encontra em graves dificuldades, pois "a função da genealogia enquanto função emancipadora do engano e auto-engano requer a identidade e a continuidade do eu que estava enganado e do eu que é e tem que ser" (MacINTYRE, 1990, p. 214). 
Para Maclntyre, a tradição aristotélico-tomista é capaz de tornar inteligível, tanto a história da moralidade moderna, como da moderna filosofia moral, de um modo que não está ao alcance daqueles que vivem nas estruturas conceituais peculiares da modernidade, sejam eles enciclopedistas ou genealogistas.

\begin{abstract}
O tomismo está, portanto, comprometido a escrever um tipo de história que ainda não foi mais que esboçada em linhas gerais. Incluída nessa história estaria a afirmação de que, como resultado da ruptura mediante a qual a moralidade se fez distinta e largamente autônoma, a moralidade se tornou vulnerável à crítica genealógica. Entretanto, apesar disso, o que essa crítica genealógica exitosamente impugna pertencer aos mesmos modos distintamente modernos de pensamento e prática, pertence também à própria genealogia. E o tomista está comprometido, portanto, a opor-se à visão de que os mesmos tipos de crítica genealógica podem ser aplicados ao pensamento e prática de Sócrates, Platão, Aristóteles, Agostinho e Tomás de Aquino como aquilo que Nietzsche e seus herdeiros implantaram contra Kant e os utilitaristas (MacINTYRE, 1990, p. 194).
\end{abstract}

Tanto o genealogista como o tomista objetivam, portanto, subverter e substituir a narrativa de progresso do enciclopedista por um tipo de história muito diferente. Todavia, eles estão, é claro, profundamente em desacordo quanto a que tipo de narração revelará os erros do enciclopedista. Para Maclntyre, o tomismo nos habilita, portanto, "para escrever um tipo de história da filosofia moderna e contemporânea que essa filosofia não pode nos oferecer por si mesma" (MacINTYRE, 2006a, p. 177). Tal história explicaria não apenas as dificuldades em que se encontra a filosofia contemporânea, mas como essas dificuldades foram produzidas e em que condições elas podem ser evitadas e superadas.

Entretanto, num atitude metodológica típica da tradição aristotélico-tomista tal como ele vem descrevendo, Maclntyre afirma que a "provisão de tal teoria requer a construção de algo semelhante ao que Nietzsche chamou uma genealogia" (MacINTYRE, 2006a, p. 172). É que a narrativa genealógica tem a função não de argumentar, mas de desvelar algo sobre as crenças, pressupostos e atividades de alguma classe de pessoa, explicando, de um modo característico, como se chegou a essas dificuldades e porque não se pode reconhecer ou diagnosticar adequadamente a 
natureza dessas dificuldades a partir dos recursos conceituais e argumentativos da própria filosofia contemporânea. Para MacIntyre, é adotando esse tipo de história genealógica que o tomismo será capaz de abrir possibilidades de diálogo e debates filosóficos com posições das quais ele não compartilha premissas ou pressupostos comuns de justificação racional ${ }^{10}$.

\section{Considerações Finais}

Diante dos conflitos incomensuráveis e irresolúveis que caracterizam a cultura contemporânea, Maclntyre defende a retomada da tradição aristotélico-tomista em detrimento da genealogia de matriz nietzschiana e da perspectiva iluminista da Enciclopédia Britânica, por ver no tomismo recursos conceituais capazes de superar tais conflitos. Para isso, ele apresenta uma leitura da história da filosofia e da investigação filosófica como uma história de rupturas profundas, na qual opera nesse envolver histórico de conflitos uma concepção de investigação como techne, tal como a entendia Aristóteles, concepção essa presente também em Platão e Tomás de Aquino.

Nessa leitura, o tomismo surge do conflito entre duas tradições conflitantes: o agostinianismo platônico e o aristotelismo. Tomás de Aquino funde essas duas tradições rivais numa tradição de pesquisa mais ampla, não apenas aperfeiçoando-as e corrigindo-as naquilo que ele considerava defeituoso ou infundado, mas também afastando aquilo que os impedia de conciliação. O interessante de tal operação realizada por Tomás de Aquino é que ele a fez mediante um método que requer que sua própria obra continuasse essencialmente incompleta, aberta a reformulações posteriores. Daí o interesse de Maclntyre em reabilitar o tomismo no interior da filosofia contemporânea, corrigindo-o e adaptando-o às demandas da atualidade.

\footnotetext{
${ }^{10}$ Ao condicionar a retomada do tomismo na filosofia contemporânea à provisão de algo semelhante a genealogia nietzschiana, Maclntyre parece estar antevendo a crítica de John Haldane, segundo a qual "para o bem ou para o mal (mais para o último, eu acho), nos lugares onde tomismo podem ser encontrados, o zeitgeist pode sugerir que, se alguma concepção saiu vitorioso do enfrentamento de concepções rivais é a pós-moderna ao invés da pré-moderna” (HALDANE, 1994, p. 100).
} 
Mais que uma filosofia substantiva, o tomismo tal como Maclntyre o descreve em Three Rival Versions of Moral Inquiry apresenta uma feição metodológica extremamente interessante, na medida em que se constitui numa tradição de pesquisa historicista e falibilista, cujo os critérios de racionalidade e verdade são internos e sujeitos a revisões posteriores. Esse aspecto metodológico da leitura macintyriana do tomismo fica evidente primeiramente quando Maclntyre descreve o modo como Tomás de Aquino resolveu o conflito entre agostinianos e aristotélicos, lendo-o como alguém que faz parte de um modo de investigação que era a continuação, dialeticamente não limitada de antemão, de uma tradição que provém de Sócrates, Platão, Aristóteles, bem como dos Padres da Igreja, tradição da qual a Aeterni Patris falou com grande precisão. Além disso, e, talvez, em decorrência dessa interpretação, outro aspecto metodológico importante dessa leitura macintyriana do tomismo é o fato de que ele vê a Summa como um guia de estudos, como uma obra em processo de elaboração. Assim, a investigação, segundo essa interpretação da Summa, torna-se um procedimento essencialmente incompleto, dialético, tal como o entendia Platão e Aristóteles, sujeito a reformulações posteriores.

Mesmo se desconsiderarmos os aspectos substantivos do giro tomista operado por Maclntyre, tal como indicamos na introdução, esse aspecto metodológico que procuramos enfatizar ao longo do texto está sujeito a objeções (ISLER, 2011). Uma primeira objeção diz respeito ao historicismo que Maclntyre atribui a Tomás de Aquino e que, no entanto, não se verifica nas obras do pensador escolástico. A resposta plausível de Maclntyre a esta objeção é que

Para aqueles que habitam uma tradição social e intelectual em bom funcionamento, os fatos da tradição, pressuposto de suas atividades e pesquisas, podem muito bem permanecer apenas isto, pressupostos inarticulados que não são objetos de atenção e pesquisa. De um modo geral, apenas quando as tradições falham, se desintegram ou são desafiadas é que seus seguidores se tornam realmente conscientes delas como tradições e começam a teorizar sobre esse substrato. Portanto, o argumento de que a maioria dos mais importantes pensadores morais e metafísicos do mundo antigo, medieval e mesmo do início do mundo moderno só podem ser compreendidos adequadamente quando situados no contexto das 
tradições, das quais a pesquisa racional era uma parte central e constitutiva, não envolve de maneira alguma o argumento de que estes pensadores escrevessem preocupados com tais tradições ou oferecessem explicações adequadas de sua natureza (MacINTYRE, 1988, p. 7-8).

Isso explica por que Tomás de Aquino e também Aristóteles, por causa de quem Maclntyre sofre a mesma objeção, não teorizam sobre a própria tradição de investigação.

No entanto, existe uma objeção mais complexa e de difícil solução: uma vez que a tradição tomista deve confrontar-se com outras tradições, inclusive correndo o risco de ser derrotada ou mesmo se fundir com essas outras, até que ponto Tomás de Aquino estaria disposto a revisar algumas de suas teses? Ele estaria disposto, por exemplo, a revisar a tese "Deus existe", uma crença essencial sobre a qual se fundamenta a tradição tomista? Essa impossibilidade de revisão de algumas das teses fundamentais do tomismo, como a acima mencionada, vai de encontro à asserção macintyriana segundo a qual "qualquer característica de qualquer tradição, qualquer teoria, qualquer prática, qualquer crença pode ser sempre, sob certas condições, colocada em questão" (MacINTYRE, 2006b, p. 12). Talvez uma saída plausível aqui seja reforçar ainda mais esses elementos metodológicos do giro tomista macintyriano, numa leitura hermenêutica que prescinda do aspecto teológico do pensamento de Tomás de Aquino. Tal possibilidade, se possível, exige um aprofundamento posterior. 


\section{Referências}

CARVALHO, Helder B. A. Tradição e racionalidade na filosofia de Alasdair Maclntyre. 2aㅡ ed. Teresina: EDUFPI, 2011.

CARVALHO, Helder Buenos Aires de. Hermenêutica e filosofia moral em Alasdair MacIntyre. Curitiba, PR: CRV, 2013.

COLEMAN, Janet. MacIntyre and Aquinas. N: HORTON, John \& MENDUS, Susan. After Maclntyre: critical perspectives on the work of Alasdair Maclntyre. Notre Dame: University of Notre Dame Press, 1994.

DÍAZ, Francisco Javier de la Torre. Alasdair Maclntyre ¿Un crítico del liberalismo? Creencias y virtudes entre las fracturas de la modernidad. Madrid: Editorial Dykinson, 2005.

GADAMER, Hans-Georg. Verdade e método I. 3a ed. Tradução de Flávio Paulo Meurer. Petrópolis: Vozes, 1997.

GEORGE, Robert P. Moral Particularism, Thomism and Traditions. Review of Metaphysics, no 42, p. 593-605, 1989.

HALDANE, John. Maclntyre's Thomist Revival: What Next? IN: HORTON, John \& MENDUS, Susan. After Maclntyre: critical perspectives on the work of Alasdair MacIntyre. Notre Dame: University of Notre Dame Press, 1994.

ISLER, Carlos. Alasdair Maclntyre: relatividad conceptual, tomismo y liberalismo. Ideas y Valores, v. 60, no 147, p. 89-111, 2011.

LUTZ, Christopher. Tradition in the Ethics of Alasdair Maclntyre. Lanham: Lexington Books, 2004.

MacINTYRE, Alasdair. After Virtue. A Study in Moral Theory. 3a ed. London: Duckworth, 2007.

MacINTYRE, Alasdair. Dependent Rational Animals: Why Human Beings Need the Virtues. Chicago: Open Court Publishing Company, 1999.

MacINTYRE, Alasdair. Epistemological crises, dramatic narrative, and the philosophy of science. IN The Tasks of Philosophy. Cambridge: Cambridge University Press, 2006b.

MacINTYRE, Alasdair. First principles, final ends, and contemporary philosophical issues. IN The Tasks of Philosophy. Cambridge: Cambridge University Press, 2006a. 
MacINTYRE, Alasdair. Three Rival Versions of Moral Inquiry: encyclopedia, genealogy and tradition. London: Duckworth, 1990.

MacINTYRE, Alasdair. Whose Justice? Which Rationality? Notre Dame: University of Notre Dame Press, 1988.

Doutorando em Filosofia pela PUCRS Professor Assistente de Filosofia /CEAD-UFPI Mestre em Filosofia/UFPI

E-mail: jose_elielton@yahoo.com.br 